\title{
Number and size of acquired melanocytic nevi and affecting risk factors in cases admitted to the dermatology clinic
}

\author{
Ayşegül Yalçınkaya İyidal', Ülker Gül², Arzu Kılıç³ \\ 1Dermatology Clinic, Ağrı State Hospital, Ağrı, Turkey \\ ${ }^{2}$ Dermatology Clinic, School of Medicine, Akdeniz University Antalya, Turkey \\ ${ }^{3}$ Dermatology Clinic, School of Medicine, Balıkesir University, Balıkesir, Turkey
}

Adv Dermatol Allergol 2016; XXXIII (5): 375-380

DOI: 10.5114/ada.2016.62845

\begin{abstract}
Introduction: The size and number of acquired melanocytic nevi (AMN) and presence of dysplastic nevi are the leading risk factors that should be recognized in the development of malignant melanoma.

Aim: To evaluate AMN and risk factors in the development of AMN in all age groups admitted to a dermatology outpatient clinic.

Material and methods: Four hundred and twelve patients who were admitted to the dermatology outpatient clinic for any dermatological symptom and who accepted to participate in the study were randomly included in the study. For each case, background-family history and dermatological findings were recorded. All AMN observed in the patients were dermatoscopically examined.

Results: The presence of more than 50 nevi was significantly higher in males, in individuals who had a history of sunburn and smokers. The number of nevi that were $5 \mathrm{~mm}$ and below was found to be higher in individuals who regularly sunbathed their face/body, in individuals using sunscreen, in individuals who had a history of sunburn, smokers and alcohol users. The number of nevi that were above $5 \mathrm{~mm}$ was higher in smokers. The total dermatoscopy score between 4.75 and 5.45 was found to be higher in individuals who had more than 50 nevi, in individuals exposed to more than one chemical substance and in alcohol users.

Conclusions: When determining the patient's risk factors, factors such as the patient's sunbathing habits and chemical substance exposure features should be taken into consideration besides the number and size of nevi.
\end{abstract}

Key words: acquired melanocytic nevi, risk factors.

\section{Introduction}

Melanocytic nevi (MN) are lesions that should be followed-up for possible development of cutaneous melanoma. The size and number of acquired melanocytic nevi $(A M N)$ and presence of dysplastic nevi (DN) are the leading risk factors that should be recognized in the development of malignant melanoma. Acquired melanocytic nevi are affected by genetic and environmental factors, and also have different data in each country depending on the patient's skin type, climatic condition of the country and racial causes [1-9].

The literature revealed that generally AMN in the children's age group were investigated and generally certain risk factors were studied [10-21]. In Turkey, no studies related to AMN including all age groups have been found yet.

\section{Aim}

The current study aimed to evaluate properties of $\mathrm{AMN}$ and risk factors in the development of $\mathrm{AMN}$ in all age groups.

\section{Material and methods}

Patients who were admitted to the dermatology outpatient clinic for any dermatological symptoms between December 2010 and February 2011 and patients who accepted to participate in the study, were randomly included. The cases using immunosuppressive treatments and who had had chemotherapy or continued to receive chemotherapy were also included. A history of sunburn, chemical substance exposure, family history of nevi, fam-

Address for correspondence: Ayşegül Yalçınkaya İyidal MD, Dermatology Clinic, Ağrı State Hospital, Ağrı Devlet Hastanesi Ek Bina, Cildiye Polikliniği, Erzurum Cad. Fırat Mah. Tedaş Karşısı Ağrı/M, 04100 Ağrı, Turkey, phone: +90 5052720042 , e-mail: aysegul762000@yahoo.com

Received: 23.03.2015, accepted: 2.10.2015. 
ily history of malignancy and/or melanoma were recorded. Dermatological and dermatoscopic examinations of all patients with AMN were performed.

The study parameters evaluated are shown in Table 1[22].

\section{Dermatological examination}

Dermatological examination of the whole body was performed under daylight when the patient was completely undressed and dermatological findings were recorded. Acquired melanocytic nevi were evaluated and classified in terms of the following groups:

- according to anatomical regions: face, scalp, nose, ear, neck, anterior trunk, posterior trunk, right-left upper and lower extremities, dorsum of the hand, palm, soles and genital region,

- number of nevi: 50 AMN or fewer, and more than 50,

- size of nevus: AMN that are $5 \mathrm{~mm}$ and smaller, and larger than $5 \mathrm{~mm}$.

\section{Dermatoscopic examination}

All AMN observed in the patients were dermoscopically examined. Total Dermatoscopy Score (TDS) was determined according to the ABCD rule for each nevus. Nevi were evaluated according to TDS: smaller than 4.75, between 4.75 and 5.45, larger than 5.45. Acquired melanocytic nevi that had TDS value of 4.75 and above were totally excised and histopathological examinations were done.

\section{Statistical analysis}

Analysis of data was conducted with SPSS for Windows 11.5 package program. The normalization of distribution of discrete numerical variables was evaluated with the Shapiro Wilk test; homogeneity of variances was evaluated with the Levene test. Descriptive statistics were demonstrated as median (minimum - maximum) for discrete numerical variables and categorical variables were demonstrated as the number of cases and percentage. The significance of difference in median values between groups was investigated with the Mann-Whitney U-test when the independent group number was two and with the Kruskal Wallis test when the independent group number was more than two. If the result of the Kruskal Wallis test statistics was significant, Conover's nonparametric multiple comparison test was used to determine the situations that caused the difference. Categorical variables were assessed with Pearson's $\chi^{2}$ or Fisher's exact $\chi^{2}$ test. The presence of a significant correlation between discrete numerical variables was investigated with Spearman's correlation test.

A value of $p<0.05$ was accepted as statistically significant.

\section{Results}

Two hundred and thirty-six (57.3\%) of 412 patients were female and 176 (42.7\%) were male. The age range was 3-90 years (median: 30). A total of 10,047 AMN were observed in 412 cases. Out of 10,047 nevi, 98.3\% were $5 \mathrm{~mm}$ and smaller, $1.7 \%$ were larger than $5 \mathrm{~mm}$. Most of the cases had type 3 skin phototype. The phenotypic characteristics of cases are displayed in Table 2.

Ninety-five (23.1\%) cases have been sunburned. Fifty (52.6\%) cases among those 95 sunburn cases defined the

Table 1 . The study parameters

\begin{tabular}{|c|c|}
\hline Gender & Male, female \\
\hline Age groups & $0-10,11-20,21-30,31-40,41-50,51-60$, and above 60 years \\
\hline Skin type & Fitzpatrick Skin Type scale was used [22] \\
\hline Hair color & Fair (blonde/scarlet), dark (brown/black) \\
\hline Eye color & Blue, green, hazel, brown \\
\hline Presence of ephelides & Present, absent \\
\hline Sunbathing behavior & Regular, irregular \\
\hline Places exposed to sun & Face-hands, face-arms, face-body \\
\hline Use of sunscreen & While sunbathing on holiday, entire summer, summer-winter \\
\hline History of sunburn & Once, more than once \\
\hline Severity of sunburn & Painful redness, blistering and with painful redness \\
\hline Exposure to chemical substances & $\begin{array}{l}\text { Absent, present (if present, inquiry about cigarettes, alcohol, pesticides, and } \\
\text { other substances (dye products, brick dust, argon gas, textile material)) }\end{array}$ \\
\hline Presence of dermatological or other cancers in cases & Absent, present \\
\hline Presence of nevi in first-degree relatives & Absent, normal, excess \\
\hline $\begin{array}{l}\text { Presence of dermatological or other } \\
\text { cancers in the family }\end{array}$ & Absent, present \\
\hline Use of immunosuppressive drugs & Absent, present \\
\hline
\end{tabular}


reaction as painful redness and the rest 45 (47.4\%) cases reported blistering.

One hundred sixty-two (39.3\%) cases had a history of chemical exposure. One hundred and fifty-two (93.8\%) of them reported cigarette exposure, 20 (12.3\%) alcohol, 16 (9.9\%) pesticide, the remaining cases reported other different chemical materials (dye products (3), brick dust (3), argon gas (2), textile material (1)). Chemical material exposure was reported once in 136 (84.0\%) cases and more than once in 26 (16\%).

The use of immunosuppressive drugs and chemotherapy was reported in 17 (4.1\%) cases.

There was a history of cancer in 15 (3.7\%) cases. Out of these, 9 (2.2\%) had extradermal skin disease and $6(1.5 \%)$ had skin cancer other than melanoma.

All cases reported presence of nevi in their family members. One hundred and twenty-two (29.6\%) cases indicated excessive presence of nevi in their families. There was a family history of cancer in 105 (25.5\%) cases. However, there was no history of melanoma.

\section{Localization of nevi}

While nevi was most frequently observed on the face, scalp and on the anterior and posterior aspects of the trunk in males, it was more frequently observed in right and left upper extremities in females (Table 3).

\section{Number of nevi}

In $61.9 \%$ of the cases, one AMN and in $38.1 \%$ of the cases, more than one MN were detected. Fifty or less nevi were observed in $89.9 \%$ of 412 cases (152 male, 218 female) while more than 50 nevi were observed in $10.1 \%$ of the cases (24 male, 18 female).

Table 2. The phenotyping characteristics of cases

\begin{tabular}{lccc}
\hline Characteristic & & Number & Percent \\
\hline Fitzpatrick skin & 1 & 2 & 0.5 \\
\cline { 2 - 4 } & 2 & 119 & 28.9 \\
\cline { 2 - 4 } & 3 & 157 & 38.1 \\
\cline { 2 - 4 } & 4 & 128 & 31.1 \\
\cline { 2 - 4 } & 5 & 6 & 1.4 \\
\hline Hair color & Dark & 408 & 99.0 \\
\cline { 2 - 4 } & Fair & 4 & 1.0 \\
\hline Eye color & Brown & 329 & 79.9 \\
\cline { 2 - 4 } & Green & 36 & 8.7 \\
\cline { 2 - 4 } & Hazel & 31 & 3.5 \\
\cline { 2 - 4 } & Blue & 16 & 93.4 \\
\hline Ephelides & Present & 27 & \\
\cline { 2 - 4 } & Absent & 385 & 3.6 \\
\hline
\end{tabular}

The number of nevi below 50 did not differ significantly between females and males, while it was more frequent in males when it is more than $50(p=0.067$, $p=0.046$; respectively).

Nevi were observed more frequently in the third decade and decreased in frequency with age in subsequent years.

No statistical difference was detected in terms of age, skin phototype, dark or fair hair color, eye color, the presence of ephelides between the two groups having more than 50 nevi and less than 50 nevi $(p=0.066, p=0.853$, $p=0.748, p=0.680$, and $p=0.748$, respectively).

A higher number of nevi on the face, on the scalp, and the anterior and posterior surfaces of the trunk were more frequent in males compared to females $(p<0.001)$. When the other anatomical regions were assessed, no statistical significance was observed $(p>0.05)$ (Table 3).

While the number of nevi on the scalp and posterior trunk significantly increased with the advanced age, the number of nevi on the palms and dorsum of the hands significantly decreased ( $p=0.021, p=0.016, p=0.018$, $p=0.024$, respectively).

The presence of more than 50 nevi in cases who had regular sunbathing behavior was greater than in cases who did not exhibit this behavior $(p=0.048)$. The number of nevi in individuals who had a history of sunburn was higher $(p=0.005)$ than those who had no history of sunburn (Table 4). However, no statistically significant correlation was found between the presence of sunburn

Table 3. Statistical evaluations according to anatomical regions in female and male cases

\begin{tabular}{|c|c|c|c|}
\hline Localization & $\begin{array}{c}\text { Male } \\
\text { min.-max. } \\
\text { (median) }\end{array}$ & $\begin{array}{c}\text { Female } \\
\text { min.-max. } \\
\text { (median) }\end{array}$ & $P$-value \\
\hline Face & $0-34(3)$ & $0-22(4.5)$ & $<0.001$ \\
\hline Nose & $0-4(0)$ & $0-3(0)$ & 0.967 \\
\hline Ear & $0-3(0)$ & $0-2(0)$ & 0.778 \\
\hline Scalp & $0-24(0)$ & $0-4(0)$ & $<0.001$ \\
\hline Neck & $0-14(0)$ & $0-16(0)$ & 0.336 \\
\hline Nape & $0-11(0)$ & $0-11(0)$ & 0.775 \\
\hline Anterior trunk & $0-40(2)$ & $0-25(1)$ & $<0.001$ \\
\hline Posterior trunk & $0-70(3)$ & $0-36(0)$ & $<0.001$ \\
\hline Right upper extremity & $0-33(2)$ & $0-40(3)$ & 0.544 \\
\hline Left upper extremity & $0-23(2)$ & $0-42(2)$ & 0.675 \\
\hline Right lower extremity & $0-12(0)$ & $0-12(0)$ & 0.426 \\
\hline Left lower extremity & $0-16(0.5)$ & 0-14 (1) & 0.889 \\
\hline Hand dorsum & $0-3(0)$ & $0-7(0)$ & 0.275 \\
\hline Palm & $0-4(0)$ & $0-3(0)$ & 0.465 \\
\hline Plantar & $0-1(0)$ & $0-1(0)$ & 0.022 \\
\hline Genital region & $0-1(0)$ & $0-1(0)$ & 0.233 \\
\hline
\end{tabular}


Table 4. The relationship between the number of nevi and sunbathing behavior, use of sunscreen and history of sunburn

\begin{tabular}{lcccc}
\hline & & 50 nevi and less & More than 50 nevi & P-value \\
\hline \multirow{2}{*}{ Sunbathing behavior } & Regular (holiday/occupational) & $128(34.6 \%)$ & $21(50.0 \%)$ & 0.048 \\
\cline { 2 - 4 } & Irregular & $242(65.4 \%)$ & $21(50.0 \%)$ & \\
\hline \multirow{2}{*}{ Use of sunscreen } & Present & $116(31.4 \%)$ & $16(38.1 \%)$ & 0.375 \\
\cline { 2 - 4 } & Absent & $254(68.6 \%)$ & $26(61.9 \%)$ & 0.005 \\
\hline History of sunburn & Present & $78(21.1 \%)$ & $17(40.5 \%)$ & \\
\cline { 2 - 4 } & Absent & $292(78.9 \%)$ & $25(59.5 \%)$ & \\
\hline
\end{tabular}

once or more and the severity of sunburn ( $p=0.317$ and $p=0.573$, respectively).

No statistically significant relation was found between the use of sunscreen and the number of nevi ( $p=0.375)$ (Table 4).

While the number of nevi in smokers was found to be higher than in nonsmokers $(p=0.004)$, no relation between exposure to other chemicals was observed $(p>0.05)$. There was no significant correlation between exposure to chemical material once or more than once and the number of nevi $(p=0.243)$.

The presence or absence of history of cancer, a high number of nevi in the family, family history of cancer, presence of systemic disease, and immunosuppressive drug use did not statistically affect the number of nevi $(p=0.337, p=0.204, p=0.518, p=0.336$, and $p=1.000$, respectively).

\section{Nevi size}

Out of a total of 10,047 AMN, 9,874 (98.3\%) were $5 \mathrm{~mm}$ or below, while $173(1.7 \%)$ were above $5 \mathrm{~mm}$. Out of 412 cases, nevi which were larger than $5 \mathrm{~mm}$ were observed in 76 (18.4\%) cases; out of these 76 cases, there was one nevi in 47 (61.9\%) cases and more than one nevi in 29 (38.1\%) cases.

The incidence of nevi that are $5 \mathrm{~mm}$ and below was found to be greater in the third decade. A prominent decrease was observed in the number of nevi after the age of 50. Nevi that were larger than $5 \mathrm{~mm}$ were observed more frequently in the fourth decade. No nevi that were larger than $5 \mathrm{~mm}$ were observed in the first decade.

The number of nevi that were $5 \mathrm{~mm}$ or below was found to be higher in individuals who regularly sunbathed the face/body ( $p=0.001)$. However, no statistical relation was found between the nevi that were above $5 \mathrm{~mm}$ and sunbathing localization $(p=0.097$ ).

The number of nevi that were $5 \mathrm{~mm}$ or below was found to be higher in individuals using sunscreen $(p=0.005)$; however, no relation was found between the duration of sunscreen use and the number of nevi $(p=0.524)$.

While the number of nevi that were $5 \mathrm{~mm}$ or below was found to be higher in individuals who had been sunburnt ( $p<0.001$ ), no statistical relation was found between the nevi that were above $5 \mathrm{~mm}$ and sunburn $(p=0.088)$.

The number of nevi that were $5 \mathrm{~mm}$ or below was found to be higher in individuals who consumed alcohol ( $p=0.010$ ), no statistical relation was found between the nevi that were above $5 \mathrm{~mm}$ and alcohol usage ( $p=0.137)$.

The number of nevi that were $5 \mathrm{~mm}$ or below and nevi that were above $5 \mathrm{~mm}$ was higher in smokers $(p=0.001$ and $p=0.036$, respectively).

No statistically significant relation was found between the nevi that were $5 \mathrm{~mm}$ and below, and above $5 \mathrm{~mm}$ with other data $(p>0.05)$.

\section{Dermatoscopic examination}

The assessment of the dermatoscopic examination of AMN is given below: < 4.75: 10,014 nevi (99.8\%), 4.755.45: 17 nevi $(0.1 \%)$, > 5.45: 16 nevi $(0.1 \%)$.

The presence of nevi with TDS between 4.75 and 5.45 was found to be higher in individuals who had more than 50 nevi $(p=0.032)$, in individuals exposed to more than one chemical substance $(p=0.012)$ and in alcohol users $(p=0.019)$. No statistically significant relation was found between TDS and other data $(p>0.05)$.

\section{Histopathological examination}

Total excision was recommended to patients with a total of 33 nevi, in which TDS was 4.75 and above. Seventeen nevi were totally excised. Other patients did not accept total excision. Out of the histopathologically examined nevi, seven were consistent with dysplastic nevi, five with dermal nevi, three with compound nevi, one with junctional nevi and one with seborrheic keratosis. Findings related to melanoma were not detected in any of the nevi. Six of the dysplastic nevi were localized on the trunk and one was on the proximal part of the lower extremity. The TDS varied between 4.9 and 7.2 .

\section{Discussion}

The incidence and mortality of cutaneous melanomas are rapidly increasing all over the world and also 
in Turkey. Thus, MN, which are a precursor of cutaneous melanomas, should be followed up. The number of AMN and the presence of dysplastic nevi are important risk factors for the development of malignant melanoma in the white population $[6,8]$.

The number of AMN depends on genetic and environmental factors. Therefore, differences are observed according to genetic structures and skin types of people living in different countries. In addition, the number of AMN varies over a lifetime. Therefore, different demographical data can be encountered in each country.

In a study performed by Dulon et al., while the average nevi number was at the least ratio in cases with skin phototype 1 , the average nevi number was detected at the highest ratio in cases with skin type 3. This was explained by the fact that individuals with skin type 1 might avoid sunlight at a higher rate and develop nevi at a lower rate [11]. In our study, no correlation was found between the skin type and the number of nevi.

More nevi were observed in individuals with brown eyes in the study of Dulon et al., in individuals with blue eyes in the study of Wiecker et al., in individuals with blue and green eyes in the studies of Valiukeviciene et al. and Dodd et al., in individuals with green and hazel eyes in the study of Whiteman et al., and in individuals with green eyes in the study of Buendia-Eisman et al. [11, 13-15, 17, 20]. Most studies reported large amounts of nevi in individuals with ephelides $[10,11,13,15-19$, 23]. In our study, no statistically significant correlation was found between eye color, hair color, ephelides and the number of nevi. No correlation between the phenotypic features of the cases and the number of nevi being 50 and fewer and the number of nevi being more than 50 was detected.

In a study conducted by Cooke et al., more nevi were detected in the upper extremities, face, and neck in females and on the back region in males [24]. Whiteman et al. did not find a significant difference between girls and boys in terms of localization of nevi in children aged 1; however, they observed nevi on the face, ears, and neck in children aged 3 and at a higher rate in boys compared to girls. However, the number of nevi in the upper and lower extremities in girls aged 3 was found to be higher than the number for boys [16]. Dodd et al. found that average nevi density was the highest on the face and neck and lateral regions of the forearms in boys and in the lateral regions of the arms and on the face and neck in girls [17]. Aguilera et al. found a higher rate of nevi on the trunk and extremities in boys when compared with girls. Furthermore, nevi were observed on the head and neck region in $61.1 \%$ of the cases [19]. BuendiaEisman et al. found that nevi were more often localized in the trunk, and in their analysis conducted according to gender, they found that nevi were more dense on the head and neck region in boys and on the lower extremities in girls [20]. In the current study, the number of nevi in male cases was greater than in female cases. In male cases, the nevi were located on the face, scalp, and anterior and posterior aspects of the trunk more frequently than in female cases.

In several studies performed in adult patients, it was demonstrated that the number of nevi decreased with age [24, 25].

Without considering the nevi size, nevi were observed more frequently in the third decade and decreased with age in the following years in our study. The percentage of nevi that were $5 \mathrm{~mm}$ and smaller was higher in the third decade; however, the percentage of nevi that were larger than $5 \mathrm{~mm}$ was found to be higher in the fourth decade. On the other hand, no correlation was detected between AMN that were greater than 50 and age.

In the assessment conducted according to gender, the incidence of more than 50 nevi in males was found to be higher than females. A similar relation was also mentioned in other studies [10, 11, 15, 19-21, 26].

Similar to the previous reports, the number of AMN in individuals that have a history of sunburn was found to be higher in our study $[10,11,14,15,17-19,26]$. Although the number of nevi in individuals using sunscreen was found to be higher in other studies, we found no correlation $[10,11]$.

In the present study, the number of nevi that is more than 50 was found to be higher in smokers and no relation with exposure to other chemicals was found. No data were found in the literature related to the correlation between the number of nevi and exposure to chemical substances.

In the present study, the number of nevi that were $5 \mathrm{~mm}$ or smaller was found to be higher in individuals who sunbathed their face/body, in individuals using sunscreen, in individuals that had been sunburned. All sized nevi were found to be higher in smokers. Harrison et al. detected a correlation between the number and severity of sunburns and nevi size. Accordingly, it was found that the individuals that had been sunburned 5-9 times had 2.2 times greater tendency to develop large MN when compared to individuals that had been sunburned 0-4 times; individuals that had been sunburned 10 times or more, had 3.5 times greater tendency to develop large MN [18]. In our study, no statistically significant correlation was found between sunburn number and AMN size.

Wiecker et al. reported a higher number of nevi in children whose parents had an excessive number of nevi on the arms [14]. Aguilera et al. found a high number of nevi in individuals who had high rates of breast cancer in the family [19]. In the current study, no relation was found between the number and size of nevi, and the presence of cancer in the family.

In the literature, no studies were found reflecting the relation between TDS and the possible risk factors for nevi. In the present study, the presence of nevi with TDS between 4.75 and 5.45 was found to be higher in 
individuals that had more than 50 nevi, in individuals exposed to more than one chemical substance and in alcohol users.

\section{Conclusions}

Our study aimed to determine the possible risk factors that affect the number and size of AMN by investigating numerous factors together in all age groups. Although there is a need for further studies on this subject, the current study is important as it is the first study on this subject in Turkey. In our research, we obtained that factors like the number of nevi and multiple chemical substance exposure (especially cigarette and alcohol usage) can also affect the TDS of patients. That is why, as the environmental factors also affect the nevus and TDS, the dermatologists should check whether there are any factors like sunbathing habits and chemical substance exposure and the clinical examination should be done by taking the factors like the skin type, number of nevus and nevus diameter in consideration. We emphasize that this study will lead dermatologists to search more studies including more demographical data and dermatoscopic features.

\section{Acknowledgments}

This research was conducted at the Numune Research and Training Hospital, Department of Dermatology, Ankara, Turkey.

\section{Conflict of interest}

The authors declare no conflict of interest.

\section{References}

1. Habif TP. Nevi and malignant melanoma. In: Clinical Dermatology. $5^{\text {th }}$ ed. Mosby-Elsevier 2010; 847-90.

2. Silva JH, Sá BC, Avila AL, et al. Atypical mole syndrome and dysplastic nevi: identification of populations at risk for developing melanoma - review article. Clinics 2011; 66: 493-9.

3. Rezze GG, Leon A, Duprat J. Dysplastic nevus (atypical nevus). An Bras Dermatol 2010; 85: 863-71.

4. Clarke LE. Dysplastic nevi. Clin Lab Med 2011; 31: 255-65.

5. Tucker MA. Atypical melanocytic nevi. In: Fitzpatrick's Dermatology in General Medicine. $7^{\text {th }}$ ed. Wolff K, Goldsmith LA, Katz S, Gilchrest AB (eds). McGrawHill, USA 2008; 1122-33.

6. Barnhill R, Rabinovitz H. Benign melanocytic neoplasms. In: Dermatology. $2^{\text {nd }}$ ed. Bolognia J, Jorizzo J, Rapini R (eds). MosbyElsevier, Spain 2008; 1713-44.

7. Tronnier M. Melanotic spots and melanocytic nevi. In: BraunFalco's Dermatology. $3^{\text {rd }}$ ed. Burgdorf WHC, Plewig G, Wolff HH (eds). Springer, Italy 2009; 1397-415.

8. Grichnic J, Rhodes A, Sober A. Benign neoplasias and hyperplasias of melanocytes. In: Fitzpatrick's Dermatology in General Medicine. $7^{\text {th }}$ ed. Wolff K, Goldsmith L, Katz S (eds). McGrawHill, USA 2008; 1099-122.

9. Emiroglu N, Cengiz FP, Hofmann-Wellenhof R. Dermoscopic and clinical features of trunk melanomas. Postep Derm Alergol 2014; 31: 362-7.
10. Pope DJ, Sorahan T, Marsden JR, et al. Benign pigmented nevi in children. Prevalence and associated factors: the West Midlands, United Kingdom Mole Study. Arch Dermatol 1992; 128: 1201-6.

11. Dulon M, Weichenthal M, Blettner $M$, et al. Sun exposure and number of nevi in 5- to 6-year-old European children. J Clin Epidemiol 2002; 55: 1075-81.

12. Bauer J, Büttner P, Wiecker TS, et al. Effect of sunscreen and clothing on the number of melanocytic nevi in 1,812 German children attending day care. Am J Epidemiol 2005; 161: 620-7.

13. Whiteman DC, Brown RM, Purdie DM, Hughes MC. Melanocytic nevi in very young children: the role of phenotype, sun exposure, and sun protection. J Am Acad Dermatol 2005; 52: 40-7.

14. Wiecker TS, Luther $\mathrm{H}$, Buettner $\mathrm{P}$, et al. Moderate sun exposure and nevus counts in parents are associated with development of melanocytic nevi in childhood: a risk factor study in 1,812 kindergarten children. Cancer 2003; 97: 628-38.

15. Valiukeviciene S, Miseviciene I, Gollnick H. The prevalence of common acquired melanocytic nevi and the relationship with skin type characteristics and sun exposure among children in Lithuania. Arch Dermatol 2005; 141: 579-86.

16. Whiteman DC, Brown RM, Purdie DM, Hughes MC. Prevalence and anatomical distribution of naevi in young Queensland children. Int J Cancer 2003; 106: 930-3.

17. Dodd AT, Morelli J, Mokrohisky ST, et al. Melanocytic nevi and sun exposure in a cohort of colorado children: anatomic distribution and site-specific sunburn. Cancer Epidemiol Biomarkers Prev 2007; 16: 2136-43.

18. Harrison SL, MacLennan R, Buettner PG. Sun exposure and the incidence of melanocytic nevi in young Australian children. Cancer Epidemiol Biomarkers Prev 2008; 17: 2318-24.

19. Aguilera P, Puig S, Guilabert A, et al. Prevalence study of nevi in children from Barcelona. Dermoscopy, constitutional and environmental factors. Dermatology 2009; 218: 203-14.

20. Buendía-Eisman A, Paláu-Lázaro MC, Arias-Santiago S, et al. Prevalence of melanocytic nevi in 8- to 10-year-old children in Southern Spain and analysis of associated factors. I Eur Acad Dermatol Venereol 2012; 26: 1558-64.

21. Akyol M, Atli AG, Ozçelik S, et al. Prevalence of common and atypical melanocytic nevi in Turkish children. Eur J Dermatol 2008; 18: 422-6.

22. Habif TP. Light-related diseases and diorders of pigmentation. In: Clinical Dermatology. $5^{\text {th }}$ ed. Mosby-Elsevier, China 2010; 741-75.

23. Vallarelli AF, Harrison SL, Souza EM. Melanocytic nevi in a Brazilian community of predominantly Dutch descent (1999-2007). An Bras Dermatol 2010; 85: 469-77.

24. Cooke KR, Spears GF, Skegg DC. Frequency of moles in a defined population. J Epidemiol Community Health 1985; 39: 48-52.

25. Schäfer T, MerkI J, Klemm E, et al.; KORA Study Group. The epidemiology of nevi and signs of skin aging in the adult general population: results of the KORA-survey 2000. J Invest Dermatol 2006; 126: 1490-6.

26. Garbe C, Buttner P, Weiss J, et al. Associated factors in the prevalence of more than 50 common melanocytic nevi, atypical melanocytic nevi, and actinic lentigines: multicenter case-control study of the Central Malignant Melanoma Registry of the German Dermatological Society. J Invest Dermatol 1994; 102: 700-5. 